\title{
Peertechz
}

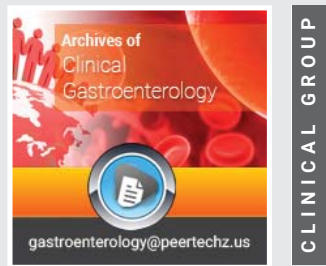

\section{Characterization of patients diagnosed with drug-induced liver injury}

\section{Itay Ashkenazi ${ }^{1 *}$, Yoav Lurie ${ }^{2 *}$, Ariel Kenig ${ }^{3}$, Shoshana Zevin $^{4,5}$, Ina Gafanovich ${ }^{2}$, Elad Resnick ${ }^{6}$, Shimon Shteingart ${ }^{7}$, Tali Bdolach-Abram ${ }^{4}$ and David E Katz ${ }^{3,4}$}

${ }^{1}$ Tel Aviv Sourasky Medical Center, Tel Aviv, Israel

2Digestive Disease Institute, Shaare Zedek Medical Center, Jerusalem, Israel

${ }^{3}$ Division of Internal Medicine, Hadassah Medical Center, Jerusalem, Israel

${ }^{4}$ Hadassah Faculty of Medicine, Hebrew University, Jerusalem, Israel

${ }^{5}$ Division of Internal Medicine, Shaare Zedek Medical Center, Jerusalem, Israel

${ }^{6}$ Division of Pediatrics, Hadassah Medical Center, Jerusalem, Israel

${ }^{7}$ Institute of Pathology, Shaare Zedek Medical Center, Jerusalem, Israel

Received: 06 May, 2021

Accepted: 29 May, 2021

Published: 01 June, 2021

*Corresponding author: Itay Ashkenazi, MD, Tel Aviv Sourasky Medical Center, 6 Weizman Street, Tel-Aviv, 6423906, Israel, Tel: +972(54)7709179;

E-mail: itay.ashkenazi@gmail.com

Keywords: Drug-induced liver injury; Antibiotics; Liver failure; International classification of disease; De ritis ratioc

https://www.peertechzpublications.com

Check for updates

\section{Abstract \\ Introduction and Objectives: Drug-induced liver injury (DILI) is the most common cause of acute liver failure in the USA, and a major cause of medication discontinuation However, DILI is often under-diagnosed, primarily due to the lack of agreed upon diagnostic criteria and limiting coding nomenclature.}

Materials and methods: We conducted a retrospective observational analysis of demographic, clinical, and laboratory data for 55 patients hospitalized in an Israeli tertiary care medical center between 2005-2017 and diagnosed with DILI.

Results: We identified 55 patients hospitalized with DILI over 12 years. DILI was associated with female gender and older age. Hepatocellular injury was the most common type of liver injury (49.0\%). Common manifestations included fever (41.8\%), weakness (41.8\%) and jaundice (34.5\%). The major offending drug group was antibiotics (35.0\%) with amoxicillin and clavulanate being the most common drugs (7.2\%). Most cases were caused by drugs administered orally (84\%), while cholestatic injury was associated with intravenous administration. De Ritis ratio (AST/ALT) was above 1.0 in $75 \%$ of cases.

Conclusions: Most DILI was caused by oral antibiotics. The incidence of DILI in our study was low, possibly due to under-diagnosis or misclassification. The adoption of the updated international classification of disease 10th edition may improve reporting rates. Utilization of the De Ritis ratio may help to differentiate between DILI and viral hepatitis.

\section{Introduction}

As all fields of medicine evolve and new medications emerge, Drug-Induced Liver Injury (DILI) is an entity of major concern. Hans Popper, one of the pioneers of modern hepatology, described this entity in 1965 [1]. Today, DILI is the leading cause of Acute Liver Failure (ALF) in the USA [2-6], and a major cause of delay in drug development, as well as drug discontinuation during treatment [7]. The numbers of reported cases of DILI are increasing $[8,9]$, including from iatrogenic causes.

However, given that there is no test for DILI, the diagnosis is usually one of exclusion $[2,10]$. This protracted process often leads to a delay in diagnosis and treatment, while there is no discontinuation of the offending drug. The difficulty in diagnosing DILI is compounded by the diverse and complex spectrum of liver pathology that share similar clinical and laboratory features (e.g., viral hepatitis) [11]. 
Several groups have attempted to develop clinical and laboratory-based scores to aid in the diagnosis of DILI [4,1215]. However, these scores were not accurate, and were found to be inferior to individual expert assessment $[10,16]$. The objectives of our study were to analyze drugs associated with DILI and characterize clinical and laboratory characteristics of patients diagnosed with DILI.

\section{Material and methods}

We conducted a retrospective observational study of all patients $\geq 18$ years of age, admitted to the Shaare Zedek Medical Center with the ICD-9 diagnostic code " 573.2 Unspecified Hepatitis", during the years of 2005 through 2017. We reviewed the medical records of these patients, and using specific criteria, this group was then divided into two groups, DILI and non-DILI patients (e.g., para-infectious hepatitis, autoimmune hepatitis, and hepatitis of unknown origin). In addition to the files of patients diagnosed with DILI, a list of all paracetamol blood tests between the years 2005-2017 was retrieved (700 tests). Of these 700 tests, we reviewed the case summaries of 30 patients who had a "positive" test (i.e., paracetamol levels $>200 \mu \mathrm{g} / \mathrm{mL}$ ).

Patient records were reviewed, and data collected included: demographics, underlying medical conditions, medications, hospital course, and laboratory data.

The patients with DILI were divided into three groups based on their alanine transaminase / alkaline phosphatase (ALT/ALKP) ratio, also known as $\mathrm{R}$ ratio $[2,4,16]$ : group $1, \mathrm{R}$ ratio $\geq 5$ indicative of hepatocellular injury; group $2, \mathrm{R}$ ratio $\leq 2$, indicative of cholestatic injury, and group 3, $2<\mathrm{R}$ ratio $<5$, indicative of mixed injury. Patients were also analyzed based on the De Ritis ratio, that is the ratio between the serum levels of Aspartate Transaminase (AST) and ALT. This ratio has been utilized in the past to represents the time course and aggressiveness of disease that would be predicted from the relatively short half-life of AST ( $18 \mathrm{~h}$ ) compared to ALT ( $36 \mathrm{~h}$ ), but not traditionally used for patients with DILI.

Descriptive statistics were calculated. The average, median, standard deviation, and range were used to describe quantitative variables, and frequency and percentage were used for qualitative variables. In order to examine the relationship between two qualitative variables, the Chi-square test and the Fisher >s exact test was used. Comparison of a quantitative variable between three categories of a qualitative variable was done using the non-parametric Kruskal-Wallis (K-W) test. Comparison of a quantitative variable between two categories of a qualitative variable was done using the t-test for two independent groups. The non-parametric $\mathrm{K}-\mathrm{W}$ test was used due to the non-normal distribution of most of the quantitative variable in the study. All statistical tests were bi-directional and $p \leq 0.05$ was considered to be statistically significant. The statistical analysis was performed using IBM SPSS Statistics version 24 . This study was approved by the institution Ethics Review Committee.

\section{Results}

The study included 55 cases of hospitalized patients who were diagnosed with DILI between 2005 and 2017. There were slightly more female patients $(55 \%)$ and the average age of all patients was 63.3 years. Table 1 shows the baseline characteristics of the patients. The mean age of women was younger than for men (60.3 vs 68.0 years), but the difference was not statistically significant. The most common type of injury was hepatocellular (49\%). The remaining patients had cholestatic injury (29\%) or mixed injury (22\%)

The number of cases increased with age, and in $40(73 \%)$ the age was 50 years or older. The occurrence of DILI in females increased during two peaks of age: 18-49 and $\geq 75$ years. Diagnosis of DILI at a young age was less common in the male population.

Table 2 lists the common clinical characteristics documented by type of liver injury. The most common clinical

Table 1: Clinical data of patients with drug-induced liver injury.

\begin{tabular}{|c|c|c|c|c|}
\hline & \multicolumn{3}{|c|}{$\mathbf{N}(\%)$} & \multirow[b]{2}{*}{ p Value } \\
\hline & $\begin{array}{l}\text { Total } \\
n=55\end{array}$ & $\begin{array}{c}\text { Female } \\
n=30(54.5)\end{array}$ & $\begin{array}{c}\text { Male } \\
\mathrm{n}=25(45.5)\end{array}$ & \\
\hline \multicolumn{5}{|l|}{ Age } \\
\hline Mean (years) & 63.8 [19.9] & $60.3[23.3]$ & 68.0 [14.2] & - \\
\hline $18-49$ & $15(27.3)$ & $12(40.0)$ & $3(12.0)$ & 0.02 \\
\hline $50-64$ & $9(16.4)$ & $3(10.0)$ & $6(24.0)$ & NS \\
\hline $65-74$ & $12(21.8)$ & $4(13.3)$ & $8(32.0)$ & NS \\
\hline$\geq 75$ & 19 (34.5) & $11(36.7)$ & $8(32.0)$ & NS \\
\hline \multicolumn{5}{|c|}{ Number of underlying medical conditionscc } \\
\hline 0 & $6(10.9)$ & $4(13.3)$ & $2(8.0)$ & NS \\
\hline $1-2$ & $14(25.5)$ & $6(20.0)$ & $8(32.0)$ & NS \\
\hline 3-4 & $18(32.7)$ & $9(30.3)$ & $9(36.0)$ & NS \\
\hline$\geq 5$ & $17(30.9)$ & $11(36.7)$ & $6(24.0)$ & NScc \\
\hline \multicolumn{5}{|l|}{ Number of chronic drugs } \\
\hline 0 & $8(14.5)$ & $5(16.7)$ & $3(12.0)$ & NS \\
\hline $1-3$ & $15(27.3)$ & $9(30.0)$ & $6(24.0)$ & NS \\
\hline $4-6$ & $13(23.6)$ & $8(26.7)$ & $5(20.0)$ & NS \\
\hline$\geq 7$ & $19(34.5)$ & $8(26.7)$ & $11(44.0)$ & NS \\
\hline \multicolumn{5}{|l|}{ Type of liver injury } \\
\hline Hepatocellular injury & $27(49.0)$ & $16(53.0)$ & $11(44.0)$ & NS \\
\hline Cholestatic injury & $16(29.0)$ & $9(30.0)$ & $7(28.0)$ & NS \\
\hline Mixed injury & $12(22.0)$ & $5(17.0)$ & $7(28.0)$ & NS \\
\hline
\end{tabular}

Standard deviation, [SD]; percentage, (\%).

Table 2: Clinical manifestations by type of liver injury.

\begin{tabular}{|c|c|c|c|c|c|}
\hline & $\begin{array}{c}\text { Total } \\
(\mathbf{n = 5 5 )}\end{array}$ & $\begin{array}{c}\text { Hepatocellular } \\
(\mathbf{n}=\mathbf{2 7})\end{array}$ & $\begin{array}{c}\text { Cholestatic } \\
(\mathbf{n = 1 6 )}\end{array}$ & $\begin{array}{c}\text { Mixed } \\
(\mathbf{n = 2 2})\end{array}$ & p-value \\
\hline Fevera & $23(41.8)$ & $10(37.0)$ & $7(43.6)$ & $6(50.0)$ & NS \\
\hline Chills & $7(12.7)$ & $4(14.8)$ & $3(18.8) c c$ & $0(0.0)$ & NS \\
\hline Weakness & $23(41.8)$ & $10(37.0)$ & $7(43.6)$ & $6(50.0)$ & NS \\
\hline Jaundice & $19(34.5)$ & $6(22.2)$ & $5(31.3)$ & $8(66.7)$ & 0.028 \\
\hline Pruritus & $6(10.9)$ & $1(3.7)$ & $0(0.0)$ & $5(41.7)$ & 0.001 \\
\hline Vomiting & $12(21.8)$ & $10(37.0)$ & $1(6.3)$ & $1(8.3)$ & 0.038 \\
\hline Abdominal pain & $11(20.0)$ & $5(18.5)$ & $4(25.0)$ & $2(16.7)$ & NS \\
\hline Anorexia & $11(20.0)$ & $6(22.2)$ & $2(12.5)$ & $3(25.0)$ & NS \\
\hline
\end{tabular}

Percentage, (\%). ${ }^{\text {a }}$ Fever was defined as a measurement of body temperature above $38^{\circ} \mathrm{C}$. DILI,: Drug-Induced Liver Injury. NS: Not Significant. 
manifestations were fever in $23(41.8 \%)$ patients, weakness in 23 $(41.8 \%)$ patients, jaundice in $19(34.5 \%)$ patients, and vomiting in $12(21.8 \%)$ patients. Less common manifestations were abdominal pain, anorexia, chills, and pruritus. Deterioration of mental status, diarrhea, headache, dark urine, acholic stool and edema were rare clinical manifestations that occurred in less than $10 \%$ of cases (not listed in the table). Vomiting occurred in patients with hepatocellular injury more than in the other types of injury $(\mathrm{p}=0.028)$. Jaundice and pruritus were statistically associated with mixed injury.

Figure 1 shows the distribution of cases according to the groups of the offending drug. The most common medications found to cause DILI were different antibiotics (35\%). The most common group of antibiotics were the $ß$-lactams ( $47 \%$ ) and the most common drug was amoxicillin and clavulanic acid (21\%). Other drugs such as non-steroidal anti-inflammatory drugs (NSAIDs), paracetamol, anticonvulsants, blood thinners, and statins were less common. Drugs that caused less than three cases, such as amiodarone, hydroxychloroquine, sulpiride, antipsychotics, or acetyl-choline esterase inhibitors, were grouped together under the heading "Other." There were $46(83.6 \%)$ patients that received medications listed as the cause of the DILI orally, and nine $(16.4 \%)$ that received these medications IV. Cholestatic injury was the most common to be caused from IV drug administration compared to hepatocellular and mixed injuries $(37.5 \%, 7.4 \%, 8.3 \%$ respectively, $\mathrm{p}=$ $0.003)$. The majority ( $78 \%)$ of the IV administered drugs were antibiotics, and $(56 \%)$ were $ß$-lactam antibiotics. The other associated antibiotics were clindamycin and chloramphenicol. Two cases associated with non-antibiotic IV drugs were related to administration of chemotherapy and the combination of Fluorouracil and Leucovorin.

The time lag between drug initiation or dose changes and the development of DILI was available in $36(65 \%)$ of the patients. The minimum recorded time lag was 3 days (paracetamol and various antibiotics), and the maximum was 330 days (for amiodarone), with the mean and median time lag being 51.4 and 14 days, respectively.

Table 3 shows the median values of the first available laboratory tests during hospitalization.

\section{Discussion}

According to the literature, approximately $1 \%$ of hospitalized patients develop DILI during hospitalization [17]. Our numbers were considerably lower than expected, and this impacted on our ability to deduce statistically significant conclusions In addition to the small number of cases, we were unable to demonstrate the increasing incidence of DILI as described in different studies $[8,9]$. Our hypothesis is that this may be due to a combination of underdiagnosis and the lack of a specific ICD-9 code for DILI. It is noteworthy that an effort to correct this oversight was done in the ICD-10 edition, but the standard term in the hepatological literature was not used, rather the term "toxic liver disease", coded as K71. We suggest that future editions would take this into account. Moreover, it should be considered to differentiate coding mechanistically (i.e., intrinsic and idiosyncratic) to assist surveillance and research.

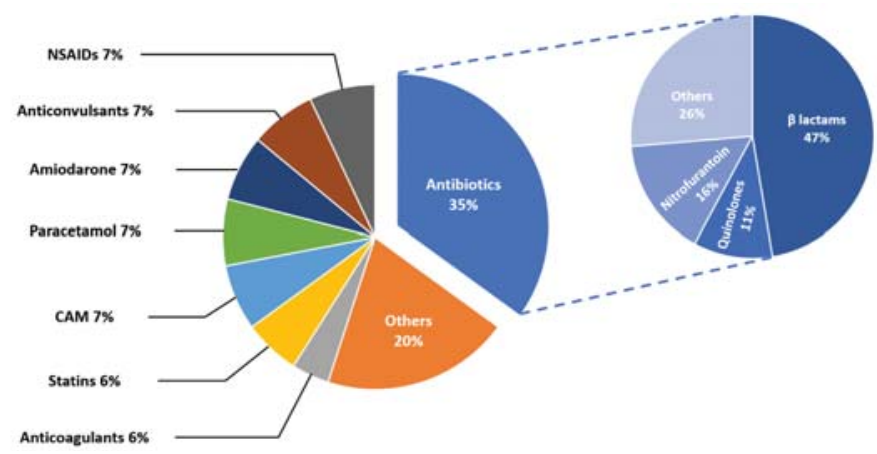

Figure 1: Distribution of DILI cases by offending drug group a (color).

a Offending drug was identified in 54 out of 55 DILI cases. CAM, complementary and alternative medications; DILI, drug-induced liver injury.c.

Table 3: Laboratory characteristic by type of liver injury.

\begin{tabular}{|c|c|c|c|c|}
\hline & $\begin{array}{c}\text { Hepatocellular } \\
(\mathbf{n = 2 7})\end{array}$ & $\begin{array}{c}\text { Cholestatic } \\
(\mathbf{n = 1 6})\end{array}$ & $\begin{array}{c}\text { Mixed } \\
(\mathbf{n = 1 2})\end{array}$ & p-value \\
\hline Age (years) & 67 & 67 & 70 & NS \\
\hline AST (U/L) & 464.0 & 72.0 & 227.0 & $<0.001$ \\
\hline ALT (U/L) & 321.0 & 52.0 & 342.5 & $<0.001$ \\
\hline ALKP (U/L) & 153.0 & 207.5 & 534.0 & 0.001 \\
\hline GGT (U/L) & 145.0 & 261.5 & 657.5 & 0.021 \\
\hline Bilirubin (mg/dL) & 1.00 & 1.60 & 6.20 & NS \\
\hline Albumin (g/dL) & 3.45 & 2.80 & 3.80 & $<0.001$ \\
\hline Platelets (x10 /L) & 246 & 237 & 208.00 & NS \\
\hline INR & 1.21 & 1.24 & 0.98 & 0.009 \\
\hline ALT/ALKP & 5.78 & 0.49 & 1.38 & $<0.001$ \\
\hline AST/ALT & 1.40 & 1.87 & 1.04 & 0.014 \\
\hline
\end{tabular}

Values represented are medians. NS: Not Significant; ALKP: Alkaline Phosphatase; ALT: Alanine Transaminase; AST: Aspartate Transaminase; GGT: Gamma Glutamyl Transferase; INR: International Normalized Ratio

To understand the low number of cases, we hypothesized that there are more DILI cases "hiding" under various ICD-9 codes. To test this, we reviewed case summaries of all 30/700 patients who tested "positive" for paracetamol between the years of 2005-2017. In 29 cases, liver enzymes (i.e. AST, ALT, etc.) did not increase, probably due to the rapid initiation of $\mathrm{n}$-acetylcysteine treatment. Only one out of 30 patients had elevated liver enzymes. The primary ICD-9 diagnosis was "suicide attempt". The word "DILI" or "573.3 - unspecified hepatitis" did not appear in the case summary. At the time of writing, and to the best of our knowledge - all hospitals in Israel still use the ICD-9 coding system.

In accordance with the literature $[2,7,18,19]$, female gender and age were shown to be risk factors, and there was a trend for females to develop DILI at a younger age. Although there are several cases of patients younger than 30, in general, the incidence of DILI increased with age, and most of our study cases were over the age of $50(73 \%)$. Our assumption is that the higher occurrence in adults results from a combination of two main factors: first, the increase in the amount of drugs (variety and dose) in older age that can directly cause DILI or increase the risk of drug interactions, and second, the increase in prevalence of multiple chronic diseases, hepatic and nonhepatic, which can increase fragility and vulnerability to drugs 
effects. We cannot comment on other risk factors mentioned in the literature $[2,7,18]$, such as different genetic factors, due to the retrospective nature of the study.

Consistent with other studies, clinical characteristics of the patients were varied [5], with the most prominent being fever, weakness, jaundice and vomiting. Other less common characteristics were anorexia, abdominal pain, and chills. Deterioration in mental status, diarrhea, headache, dark urine, acholic stool, edema, and pruritus were also documented in a small number of cases. There was one death due to terbinafine, and one patient was diagnosed with symptomatic cirrhosis due to amiodarone.

The most common drugs to cause DILI can vary between different countries. For example, in a studies from Korea [20] and more recently from China [21] it was found that complementary and alternative medications (CAM) are the most common drugs to cause DILI, whereas in the USA the most common drugs are antimicrobial drugs [22]. Similar to the results of the American study, the most common drugs to cause DILI in our study were antibiotics of various types (35\% of patients). The most common antibiotic group was ß-lactam (47\% of antibiotics). The "other drugs" group constituted a significant portion of the cases $(20 \%)$. We speculate that this is mainly due to the difficulty in creating "groups" out of drugs that cause small portion of the cases, combined with a relatively low number of cases in the study. This phenomenon has been observed and was already described [18]. Paracetamol, statins, anticonvulsants, blood thinners, antipsychotics, NSAIDs and food supplements less commonly caused DILI. This may be due to the fact that a large proportion of the cases of DILI due to these drugs are diagnosed in an early stage by their primary physician (due to a high index of suspicion) and do not end in hospitalization. In $84 \%$ of our DILI cases, the offending drug administration method was PO. Most DILI patients receiving IV medication developed a cholestatic injury pattern (37\%), compared to hepatocellular $(7.4 \%)$, or mixed patterns $(8.3 \%)$.

DILI's diagnosis is based on establishing the temporal relationship between drug administration and the appearance of signs and symptoms. That is, to examine whether a reasonable period of time has passed between taking the drug and developing DILI. It is generally accepted that this period of time is at least 3 days, with a range of 2-10 weeks [2]. This period of time was documented in $36(65 \%)$ of our study patients. Several scoring systems, such as the Roussel Uclaf Causality Assessment Method (RUCAM) scoring system, aim to assess causality [23]. However, they still regarded as a supportive tool for expert opinion in current guidelines [10]. Furthermore, when relying on case documentation, the application of this scale retrospectively can lead to biased results in poorly documented cases [6].

As in previous studies [5,24], most patients (49\%) showed hepatocellular injury. The remainder showed cholestatic injury (29\%) or mixed injury (22\%). A statistically significant difference was found in the levels of AST, ALT, ALKP and Gamma-Glutamyl Transferase (GGT), as well as the ALT/ALKP ratio ( $\mathrm{R}$ ratio) between the different types of injury. This is not surprising given the fact that the definition of the different types of injury is based on the differences in these enzyme levels. Median values were chosen over mean value due to the effect of outliers on the mean, especially since the sample size was relatively small. Thus, drugs that caused liver enzymes to rise to levels of thousands of units / liter, such as paracetamol and diphenylhydantoin, contributed to a significant increase of the mean compared to the median.

The AST/ALT ratio (De Ritis ratio) often can serve as a diagnostic aid. For example, in the case of alcoholic hepatitis, the De Ritis ratio $>2$ is known to be highly supportive [25]. In our study, the median De Ritis ratio in all types of injury, as shown in Table 3, was greater than 1 . Moreover, 41 (75\%) patients in the study had a De Ritis $>1$ ratio. The De Ritis ratio was greater than 0.70 in 11 of the 14 remaining patients. This is in marked contrast to viral hepatitis, where the De Ritis ratio is usually less than 1 (except in cases of severe viral hepatitis) [26-28], usually in the range of 0.5-0.7 [28]. The De Ritis ratio's ability to assist in the distinction between viral hepatitis and DILI in the individual patient is not as well described as it is for alcoholic hepatitis $[25,28]$. It should be noted that the results in Lee, et al. [20] were reversed, that is, the De Ritis ratio was $<1$ in their DILI cohort (as in viral hepatitis), but this may be attributed to ethnic variance (i.e., this was research done in Korea) or variance in the type of drugs. It should be noted, however, that as the De Ritis ratio is unspecific, it can only serve as a supportive, rather than a diagnostic finding.

The cases examined in our study were relatively mild, as expressed in the low mortality rate $(1 / 55)$, the incidence of cirrhosis (1/55), and in the low bilirubin levels. We also lack information regarding patient prognosis or changes in liver function after hospital discharge. This would be important as progression to chronic DILI can occur in about $5.7 \%$ of cases [29]. We can assume that there was no progression to significant liver disease after discharge as we are likely to have seen evidence of this in the computerized files of the hospital.

The lack of uniform follow-up of patients made it impracticable for us to track long term changes in liver enzymes, and it may be that a prospective study is required to address this issue. There may have been a bias for patients who improved significantly, and therefore were discharged earlier to follow-up in the community. For these patients, complete enzymatic curves describing a return to normal, or progression from acute to chronic DILI, would be lacking. We tried to assess severity of DILI using length of stay. However, this may have been confounded by patients where the DILI resolved, but the hospitalization continued due to their primary unrelated underlying disease.

Despite the increasing incidence of DILI according to literature, we were not able to confirm this trend. This may have been due to the absence of a specific diagnostic code for DILI in the ICD-9 coding system. Patients whose main diagnosis is DILI are coded under another major diagnosis and the DILI is "hidden" under a general hepatic diagnosis such as "elevated liver enzymes" or even under a non-hepatic diagnosis as a free text. 
We submit that the ICD-10 coding system which does include DILI as a major diagnosis, should be adopted. We also suggest the implementation of De Ritis ratio as a diagnostic aid, with the note that other liver disease might present with a similar ratio. While viral hepatitis is characterized by a De Ritis ratio $<1$, most of the patients in our study $(75 \%)$ had a De Ritis ratio $>1$. This potential finding should be reproduced in larger studies. Further research should also be expanded to follow patients in the community prospectively, allowing for better data capture of changes in liver enzymes, progression to chronic DILI, clinical course, and overall prognosis. The establishment of a national DILI registry (involving all medical institutions), similar to other countries, would be vital to further studies.

\section{References}

1. Popper H, Rubin E, Gardiol D, Schaffner F, Paronetto F (1965) Drug-Induced Liver Disease: A Penalty For Progress. Arch Intern Med115: 128-136. Link: https://bit.ly/3p4eHTX

2. Schiff ER, Maddrey WC, Sorrell MF (2012) Schiff's diseases of the liver Chichester. West Sussex, UK: John Wiley \& Sons. Link: https://bit.ly/2RQddRa

3. Agarwal VK, McHutchison JG, Hoofnagle JH (2010) Important Elements for the Diagnosis of Drug-Induced Liver Injury. Clin Gastroenterol Hepatol. Clin Gastroenterol Hepatol 8: 463-470. Link: https://bit.ly/34u5RFA

4. Kaplowitz N (2001) Causality assessment versus guilt-by-association in drug hepatotoxicity. Hepatology. 33: 308-310. Link: https://bit.ly/3p4WW6V

5. Fauci AS (2015) Harrison's principles of internal medicine. McGraw-Hill Education. Link: https://bit.ly/3p5V8dL

6. Andrade RJ, Chalasani N, Björnsson ES, Suzuki A, Kullak-Ublick GA, et al (2019) Drug-induced liver injury. Nat Rev Dis Prim Nature Publishing Group 5. Link: https://bit.ly/3vHCZFK

7. Lewis JH (2015) The Art and Science of Diagnosing and Managing Drug induced Liver Injury in 2015 and Beyond. Clin Gastroenterol Hepatol W.B. Saunders 2173-2189.e8. Link: https://bit.ly/2S0e1mr

8. Devarbhavi H, Dierkhising R, Kremers WK, Sandeep MS, Karanth D, et al. (2021) Single-center experience with drug-induced liver injury from india: Causes, outcome, prognosis and predictors of mortality. Am J Gastroenterol 105: 2396-2404. Link: https://bit.ly/3p6WkOj

9. Hillman L, Gottfried M, Whitsett M, Rakela J, Schilsky M, et al. (2016) Clinica Features and Outcomes of Complementary and Alternative Medicine Induced Acute Liver Failure and Injury. Am J Gastroenterol 111: 958-965. Link: https://bit.ly/3wFqBWl

10. Chalasani NP, Maddur H, Russo MW, Wong RJ, Reddy KR (2021) ACG Clinical Guideline: Diagnosis and Management of Idiosyncratic Drug-Induced Liver Injury. Am J Gastroenterol 116: 878-898. Link: https://bit.ly/2S13C9X

11. Senior JR (2014) Evolution of the Food and Drug Administration Approach to Liver Safety Assessment for New Drugs: Current Status and Challenges. Drug Saf. Springer International Publishing 9-17. Link: https://bit.ly/3g0ExE2

12. Tajiri K, Shimizu Y (2008) Practical guidelines for diagnosis and early management of drug-induced liver injury [Internet]. World J. Gastroenterol. Baishideng Publishing Group Co 6774-6785. Link: https://bit.ly/3fDpMIC

13. Maria VAJ, Victorino RMM (1997) Development and validation of a clinical scale for the diagnosis of drug-induced hepatitis. Hepatology John Wiley and Sons Inc 26: 664-669. Link: https://bit.ly/3wPhV0j

14. Benichou C, Danan G, Flahault A (2021) Causality assessment of adverse reactions to drugs-II. An original model for validation of drug causality assessment methods: Case reports with positive rechallenge. J Clin Epidemiol 46: 1331-1336. Link: https://bit.ly/2R67ENU

15. García-Cortés M, Lucena MI, Pachkoria K, Borraz Y, Hidalgo R, et al. (2021) Evaluation of Naranjo Adverse Drug Reactions Probability Scale in causality assessment of drug-induced liver injury. Aliment Pharmacol Ther. Blackwell Publishing Ltd 27: 780-789. Link: https://bit.ly/3wKyGtw

16. Fisher K, Vuppalanchi R, Saxena R (2015) Drug-induced liver injury. Arch Pathol Lab Med 876-887. Link: https://bit.ly/3c6zS2q

17. Meier $Y$, Cavallaro M, Roos M, Pauli-Magnus $C$, Folkers $G$, et al. (2005) Incidence of drug-i'nduced liver injury in medical inpatients. Eur $\mathrm{J}$ Clin Pharmacol 61: 135-143. Link: https://bit.ly/34ycDKA

18. Lucena MI, Andrade RJ, Kaplowitz N, García-Cortes M, Fernández MC, et al. (2009) Phenotypic characterization of idiosyncratic drug-induced liver injury: The influence of age and sex. Hepatology 49: 2001-2009. Link: https://bit.ly/3vEMmWy

19. Björnsson ES (2020) Epidemiology, Predisposing Factors, and Outcomes of Drug-Induced Liver Injury. Clin Liver Dis W.B. Saunders 1-10. Link: https://bit.ly/3paiijd

20. Lee BM, Lee WC, Jang JY, Ahn P, Kim JN, et al. (2015) Clinical features of drug induced liver injury according to etiology. J Korean Med Sci 30: 1815-1820. Link: https://bit.ly/3c5QKpP

21. Shen T, Liu Y, Shang J, Xie Q, Li J, et al. (2021) Incidence and Etiology of Drug Induced Liver Injury in Mainland China. Gastroenterology 156: 2230-2241.e11. Link: https://bit.ly/3wNUmoi

22. Norris W, Paredes AH, Lewis JH (2021) Drug-induced liver injury in 2007. Curr Opin Gastroenterol 287-297. Link: https://bit.ly/3g12Lyb

23. Aithal GP, Watkins PB, Andrade RJ, Larrey D, Molokhia M, et al. (2011) Case definition and phenotype standardization in drug-induced liver injury. Clin Pharmacol Ther. Clin Pharmacol Ther 89: 806-815. Link: https://bit.ly/3fSkZ40

24. Robles-Diaz M, Garcia-Cortes M, Medina-Caliz I, Gonzalez-Jimenez A, Gonzalez Grande R, et al. (2015) The value of serum aspartate aminotransferase and gamma-glutamyl transpetidase as biomarkers in hepatotoxicity. Liver Int 35 2474-2482. Link: https://bit.ly/3fVTB5R

25. Majhi S, Baral N, Lamsal M, Mehta KD (2006) De Ritis ratio as diagnostic marker of alcoholic liver disease. Nepal Med Coll J 8: 40-42. Link: https://bit.ly/3c62k4r

26. Gitlin N (1982) The Serum Glutamic Oxaloacetic Transaminase/Serum Glutamic Pyruvic Transaminase Ratio as a Prognostic Index in Severe Acute Viral Hepatitis. Am J Gastroenterol 77: 2-8. Link: https://bit.ly/3fBNSmV

27. Deritis F, Giusti G, Piccinino F, Cacciatore L (1965) biochemical laboratory tests in viral hepatitis and other hepatic diseases. Evaluation and follow-up Bull World Health Organ 32: 59-72. Link: https://bit.ly/34LBkTX

28. Botros M, Sikaris KA (2013) The de ritis ratio: The test of time. Clin Biochem Rev 34: 117-130. Link: https://bit.ly/3c3N1ZY

29. Andrade RJ, Lucena MI, Kaplowitz N, García-Munoz B, Borraz Y, et al. (2006) Outcome of acute idiosyncratic drug-induced liver injury: Long-term follow-up in a hepatotoxicity registry. Hepatology 44: 1581-1588. Link: https://bit.ly/34yR4ti

Copyright: @ 2021 Ashkenazi I, et al. This is an open-access article distributed under the terms of the Creative Commons Attribution License, which permits unrestricted use, distribution, and r eproduction in any medium, provided the original author and source are credited.

Citation: Ashkenazi I, Lurie Y, Kenig A, Zevin S, Gafanovich I, et al. (2021) Characterization of patients diagnosed with drug-induced liver injury. Arch Clin Gastroenterol 7(2): 036-040. DOI: https://dx.doi.org/10.17352/2455-2283.000095 